\title{
Increased frequencies of memory and activated $B$ cells and follicular helper $T$ cells are positively associated with high levels of activation-induced cytidine deaminase in patients with immunoglobulin A nephropathy
}

\author{
YING SUN ${ }^{1}$, ZHIHONG LIU ${ }^{2}$, YING LIU ${ }^{1}$ and XIA LI $^{3}$ \\ Departments of ${ }^{1}$ Dermatology and ${ }^{2}$ Ophthalmology, \\ The Affiliated Hospital of Changchun University of Chinese Medicine, Changchun, Jilin 130021; \\ ${ }^{3}$ Department of Neurology, The Third Affiliated Hospital of Beijing University of Chinese Medicine, \\ Beijing 100029, P.R. China
}

Received August 20, 2014; Accepted June 9, 2015

DOI: $10.3892 / \mathrm{mmr} .2015 .4071$

\begin{abstract}
The aim of the present study was to examine the frequencies of different subsets of $B$ and follicular helper T (Tfh) lymphocytes in patients with immunoglobulin A nephropathy (IgAN), and investigate the potential underlying mechanism. A total of 27 patients with $\operatorname{IgAN}$ and 10 healthy controls ( $\mathrm{HC}$ ) were recruited for analysis of the frequencies of different subsets of B and Tfh cells. ELISA was used to analyze the concentration of serum interleukin (IL)-21. The transcriptional levels of activation-induced cytidine deaminase (AID) in the $\mathrm{B}$ cells were determined using reverse transcription-quantitative polymerase chain reaction, while the translational levels of AID were analyzed using western blotting. The frequencies of circulating memory and activated B cells and Tfh cells were found to be significantly increased in the IgAN groups, compared with those of the HC group, although the number of plasma cells were not significantly different between the two IgAN groups. In addition, the serum levels of IL-21 were found to be higher in the patients with $\operatorname{IgAN}$, and correlated with 24-h proteinuria. IL-21 also enhanced the expression levels of AID in the B cells. The data of the present study revealed that the high levels of memory and activated B cells and Tfh cells were positively associated with the progression of $\operatorname{IgAN}$, and that this may be mediated by the overexpression of AID, which is potentially regulated by IL-21.
\end{abstract}

Correspondence to: Professor Xia Li, Department of Neurology, The Third Affiliated Hospital of Beijing University of Chinese Medicine, 51 Xiaoguan Street, Beijing 100029, P.R. China E-mail: xiali815@163.com

Key words: immunoglobulin A nephropathy, B cells, follicular helper T cells, interleukin-21, activation-induced cytidine deaminase

\section{Introduction}

Immunoglobulin A nephropathy ( $\operatorname{Ig} \mathrm{AN}$ ) is considered to be the most common type of glomerular disease worldwide (1). IgAN has been confirmed to be an immune complex-mediated glomerulonephritis, defined morphologically by the mesangial deposition of $\operatorname{Ig}$ A $(2,3)$. Although defects in immune regulation are considered to be important in the pathogenesis of IgAN, the pathogenetic mechanisms remain to be fully elucidated. Previous studies have reported that IgAN is regulated by $\mathrm{B}$ lymphocytes $(4,5)$, and increased numbers of $\mathrm{T}$ helper (CD4) lymphocytes and reduced numbers of $\mathrm{T}$ suppressor (CD8) lymphocytes are associated with the exacerbation of $\operatorname{IgAN}(6,7)$. However, overproduction of $\operatorname{Ig} \mathrm{A}$ is most likely the consequence of the involvement of both $\mathrm{T}$ and B lymphocytes.

The present study aimed to explore immune status alterations during the progression of IgAN disease. The distributions of different B-cell subsets and Tfh cells were analyzed in patients with $\operatorname{IgAN}$ at various disease phases, and the differential contributions of these lymphocytes to IgAN were evaluated. To explain the imbalance of B-cell subsets, the main effector of Tfh cells, IL-21 was also investigated.

IL-21 is not a classic T helper cell 1 or 2 cytokine, but is mainly produced by CD4+ follicular T helper cells, which can be identified by their expression of the chemokine receptor CXCR5. The high levels of IL-21 receptor (IL-21R) expressed by B cells make B cells prime responders to IL-21. B cells faced with IL-21 in the context of antigen-specific BCR stimulation and $\mathrm{T}$ cell co-stimulation undergo class switch recombination and differentiate into antibody producing plasma cells $(8,9)$. Activation-induced cytidine deaminase (AID) induces somatic hypermutation, gene conversion, and class-switch recombination of immunoglobulin genes in B cells $(10,11)$. Thus, it is important to clarify the association between IL-21 and AID expression, which may aid understanding of the functions of $\mathrm{T}$ helper cells and different B-cell subsets in the process of IgAN disease. 


\section{Materials and methods}

Patients.Atotal of 27patientsdiagnosed with IgANwererecruited for investigation from the Department of Gastroenterology at the Affiliated Hospital of Changchun University of Chinese Medicine (Changchun, China) between 2012 and 2013. The diagnoses of IgAN in the patients were confirmed by biopsy and the presence of proteinuria. The patients with IgAN were divided into two groups, according to the extent of proteinuria: Group A ( $\mathrm{n}=12)$, proteinuria $<4 \mathrm{~g} / 24 \mathrm{~h}$; group B $(\mathrm{n}=15)$, proteinuria $\geq 4 \mathrm{~g} / 24 \mathrm{~h}$. Patients who had received immunosuppressive therapies in the 6 months preceding the investigation were excluded. A total of 10 gender- and age-matched healthy volunteers were selected as the HC group, each of which were recruited from the Department of Physical Examination Center of the Affiliated Hospital of Changchun University of Chinese Medicine. None of the patients or controls had any systemic disorders, viral infections or other autoimmune diseases. All study participants provided written informed consent, and the ethical committee of the Affiliated Hospital of Changchun University of Chinese Medicine approved the experiment. The clinical characteristics of the patients and $\mathrm{HC}$ individuals are presented in Table I.

PBMC culture and stimulation. Peripheral blood mononuclear cells (PBMCs) were isolated from venous blood samples of all patients using standard Ficoll-Paque Plus (GE Healthcare Life Sciences, Pittsburgh, PA, USA) density-gradient centrifugation $(1,500 \mathrm{x}$ g for $10 \mathrm{~min}$ at room temperature). Subsequent to washing in phosphate-buffered saline (PBS), the PBMCs were diluted at $4 \times 10^{6} / \mathrm{ml}$ in Dulbecco's modified Eagle's medium (GE Healthcare Life Sciences, Logan, UT, USA), containing 10\% fetal bovine serum (Gibco Life Technologies, Carlsbad, CA, USA) and penicillin-streptomycin (100 U/ml) solution (GE Healthcare Life Sciences) and were cultured in 24-well plates (Corning Incorporated, Corning, NY, USA). The isolated PBMCs were cultured with CpGB $(3 \mu \mathrm{g} / \mathrm{ml}$; R\&D Systems, Inc., Minneapolis, MN, USA) and $10 \mathrm{ng} / \mathrm{ml}$ recombinant interleukin (IL)-2 (R\&D Systems, Inc.) for $72 \mathrm{~h}$ to detect $\mathrm{B}$ cell sub-populations. In order to stimulate $\mathrm{T}$ cells, $50 \mathrm{ng} / \mathrm{ml}$ phorbol myristate acetate, $1.0 \mathrm{mg} / \mathrm{ml}$ ionomycin and $5.0 \mathrm{mg} / \mathrm{ml}$ lipopolysaccharide (all from Sigma-Aldrich, St. Louis, MO, USA) were cultured with the PBMCs for $2 \mathrm{~h}$ at $37^{\circ} \mathrm{C}$. Subsequently, Brefeldin A (BD Biosciences, Franklin Lakes, NJ, USA) was added to each well and they were incubated for an additional $4 \mathrm{~h}$ at $37^{\circ} \mathrm{C}$.

Flow cytometric analysis. To analyze the distribution of different B cells subsets and Tfh cells, the PBMCs were stimulated in vitro, as described above, and then harvested, washed with ice-cold PBS, and stained with fluorescein-labeled monoclonal antibodies (1:500 dilution) against various B cell markers [anti-CD19 PerCP (cat. no. 340421), anti-CD27 APC (cat. no. 561786), anti-CD86 cy5.5 (cat. no. 561129), anti-CD138 fluorescein isothiocyanate (cat. no. 561703)] and Tfh cells [anti-CXCR5 PerCP (cat. no. 562781) and anti-CD4 APC (cat. no. 340443)]. All antibodies were from BD Pharmingen (San Diego, CA, USA). The control PBMCs were cultured in medium alone. Following a $1 \mathrm{~h}$ incubation with the primary antibodies at room temperature, the cells were washed with
PBS, and at least 20,000 events were recorded. The data was obtained using a FACSCalibur analytical instrument (BD Biosciences) and four-color analysis was performed using FlowJo software, version 7.6 (FlowJo, LLC, Ashland, OR, USA).

ELISA. The serum level of IL-21 was quantified in the IgAN patients and HC individuals using a Human IL-21 ELISA kit, according to the manufacturers' instructions (Roche Diagnostics, Ltd, Burgess Hill, UK). The plate was read at $450 \mathrm{~nm}$ using an Infinite M200pro plate reader (Tecan, Männedorf, Switzerland) and the sensitivity of the ELISA kits used in the experiment was $19 \mathrm{pg} / \mathrm{ml}$. All samples were analyzed in duplicate using the average optical density values to calculate the concentrations.

Determination of the effect of IL-21 on levels of AID. To detect the expression of AID, the B cells were collected from the PBMCs of the HC group, were stained with anti-CD19 PerCP and anti-CD3 PE antibodies, and were sorted using a FACSAria flow cytometer (BD Biosciences). The purified B cells were identified as CD3-CD19+ cells. The isolated B cells were cultured with recombinant human IL-21 (20 ng/ml; Peprotech, Inc., Rocky Hill, NJ, USA), CpGB (3 $\mu \mathrm{g} / \mathrm{ml})$ and recombinant IL-2 $(10 \mathrm{ng} / \mathrm{ml})$ for $72 \mathrm{~h}$, and were then lysed on ice for $30 \mathrm{~min}$ in radioimmunoprecipitation assay buffer (Beytoime Institute of Biotechnology, Haimen, China), containing $50 \mathrm{mM}$ Tris- $\mathrm{HCl}$ (pH 7.4), $150 \mathrm{mM} \mathrm{NaCl}, 0.1 \%$ SDS, $1 \%$ deoxycholate, $1 \%$ Triton X-100, 1 mM EDTA, $5 \mathrm{mM} \mathrm{NaF}, 1 \mathrm{mM}$ sodium vanadate and protease inhibitor cocktail. Following quantification of the proteins with a Bicinchoninic Acid Protein Assay kit (Beyotime Institute of Bioechnology), the total proteins $(70 \mu \mathrm{g})$ were then subjected to $10 \%$ SDS-PAGE (Beyotime Institute of Biotechnology), and transferred onto a nitrocellulose membrane (Pall Corporation, Port Washington, NY, USA). The membrane was incubated with primary antibodies targeting AID and GAPDH (1:2,000 dilution; cat. nos. sc-25620 and sc-25778; Santa Cruz Biotechnology, Inc., Dallas, TX, USA). The animal-matched horseradish peroxidase-conjugated secondary antibody was also purchased from Santa Cruz Biotechnology, Inc. (1:2,000 dilution; cat. no. sc-2370). The total RNA of these cultured cells was extracted using TRIzol reagent (Invitrogen Life Technologies, Carlsbad, CA, USA). Total RNA ( $1 \mu \mathrm{g})$ was used for cDNA synthesis using the RevertAid First Strand cDNA Synthesis kit (Thermo Fisher Scientific, Inc., Waltham, MA, USA). PCR was performed using Hot Start Taq DNA Polymerase (Takara Bio Inc., Otsu, Japan), and PCR cycling conditions were as follows: $94^{\circ} \mathrm{C}$ for $3 \mathrm{~min}$, followed by 35 cycles at $94^{\circ} \mathrm{C}$ for $30 \mathrm{sec}, 58^{\circ} \mathrm{C}$ for $30 \mathrm{sec}$ and $72^{\circ} \mathrm{C}$ for $45 \mathrm{sec}$, and a final extension step at $72^{\circ} \mathrm{C}$ for $10 \mathrm{~min}$. Differences in the expression levels of cDNA were normalized to GAPDH. The primer [Generay Biotech (Shanghai) Co., Ltd., Shanghai, China] sequences were as follows: AID, forward 5'-CAATAAGAACGGCTGCCAC -3 ' and reverse 5'-TTGCGGTCCTCACAGAAGTAG-3'; and GAPDH, forward 5'-CACCAACTGGGACGACAT-3' and reve rse 5'-ACAGCCTGGATAGCAACG-3'.

Statistical analysis. All data are expressed as the mean \pm standard deviation in the text and figures. Statistical 
Table I. Clinical and pathological manifestations of the patients with IgAN and the HC individuals.

\begin{tabular}{|c|c|c|c|}
\hline Parameter & $\begin{array}{c}\text { IgAN group A } \\
(24-\mathrm{h} \text { proteinuria }<4 \mathrm{~g})\end{array}$ & $\begin{array}{c}\text { IgAN group B } \\
(24-\mathrm{h} \text { proteinuria } \geq 4 \mathrm{~g})\end{array}$ & $\mathrm{HC}$ \\
\hline Number & 12 & 15 & 10 \\
\hline Age (years) & $58(40-63)$ & $47(30-66)$ & $27(18-40)$ \\
\hline Female/male & $5 / 7$ & $8 / 7$ & $4 / 6$ \\
\hline Serum IgA (g/l) & $4.97(4.36-7.81)^{\mathrm{a}}$ & $5.85(4.08-6.22)^{\mathrm{a}}$ & $1.82(1.13-2.77)$ \\
\hline Serum uric acid (mol/l) & $343(247-634)$ & $357(271-603)$ & $320(230-370)$ \\
\hline eGFR (ml/min/1.73 $\left.\mathrm{m}^{2}\right)$ & $71(32-89)^{\mathrm{a}}$ & $56(40-126)^{\mathrm{a}}$ & $103(90-129)$ \\
\hline
\end{tabular}

Data are presented as the real case number or the median (range). ${ }^{\mathrm{P}}<0.05$, vs. HC. IgAN, immunoglobulin A nephropathy; HC, healthy control; eGFR, estimated glomerular filtration rate.

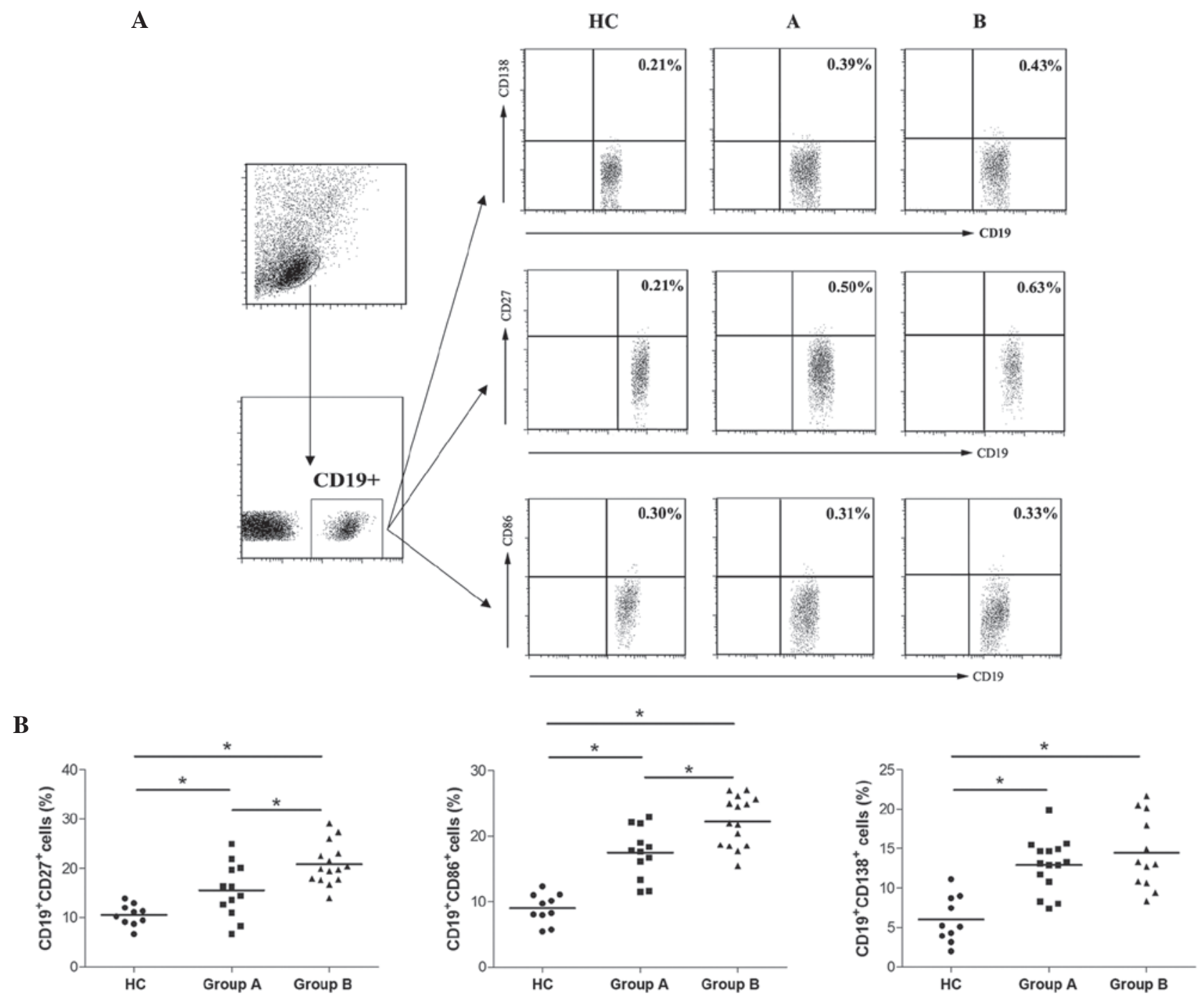

Figure 1. Fluorescence-activated cell sorting analysis of the frequency of different subsets of B cells in the IgAN (groups A and B) and HC groups. PBMCs $\left(5 \times 10^{5}\right)$ were stained with anti-CD19 PerCP, anti-CD27 APC, anti-CD86 cy5.5 and anti-CD138 fluorescein isothiocyanate for B cell subset analysis. (A) Representative results of the frequency of each group of B cell subsets, measured using flow cytometry. (B) Percentages of the different subsets of $\mathrm{B}$ lymphocytes in the IgAN and $\mathrm{HC}$ groups ( $\mathrm{P}<0.05)$. Each data point represents an individual subject, and the horizontal lines represent the median. IgAN, immunoglobulin A nephropathy; HC, healthy controls; group A, 24-h proteinuria $<4$ g; group B, 24-h proteinuria $\geq 4 \mathrm{~g}$.

analyses were conducted using GraphPad Prism 5.0 software (GraphPad Software, Inc., La Jolla, CA, USA). Significant differences were calculated using the two-tailed, unpaired
Student's t-test, with a $95 \%$ confidence interval. $\mathrm{P}<0.05$ (two-tailed) was considered to indicate a statistically significant difference. 
A
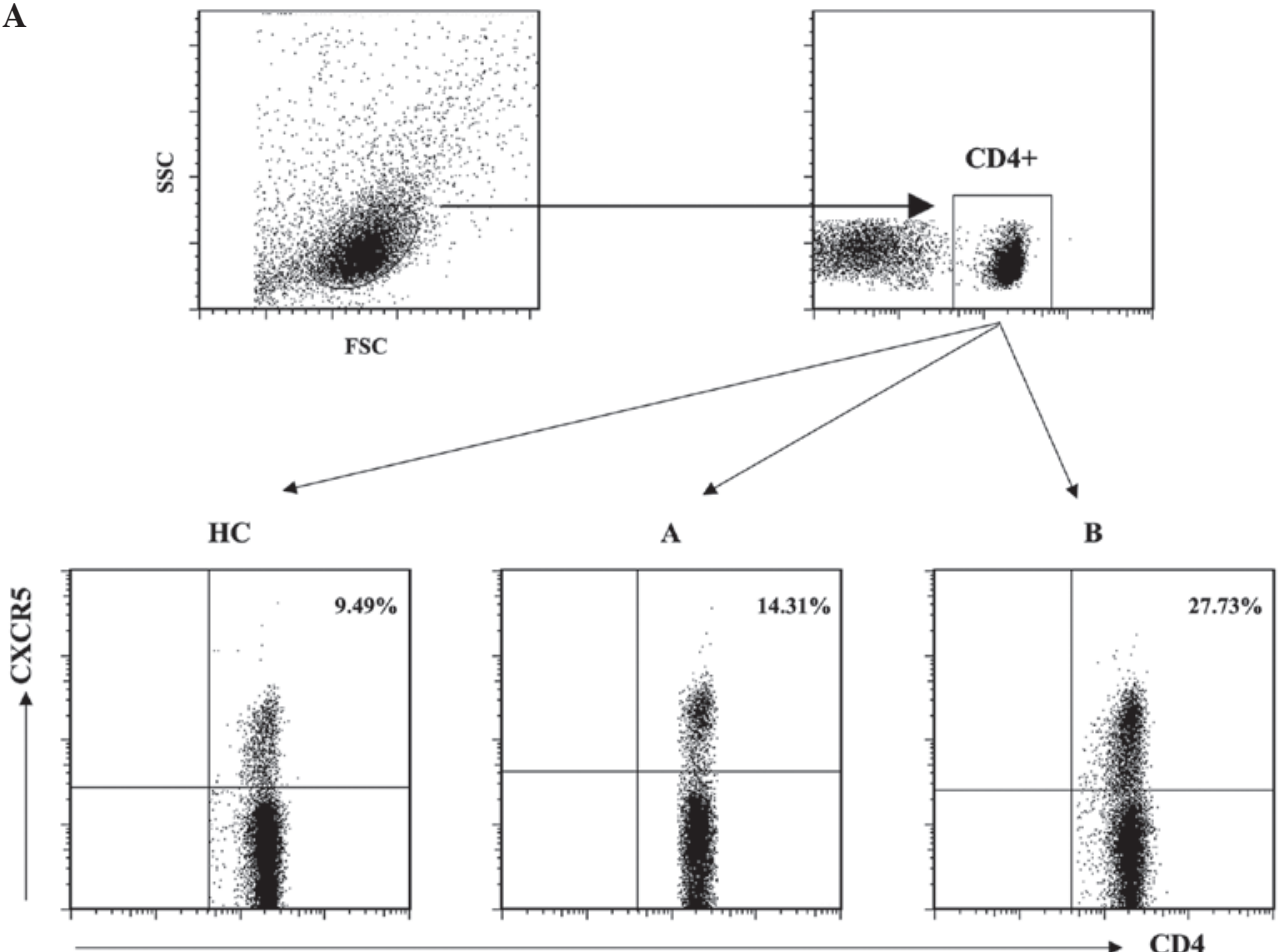

B

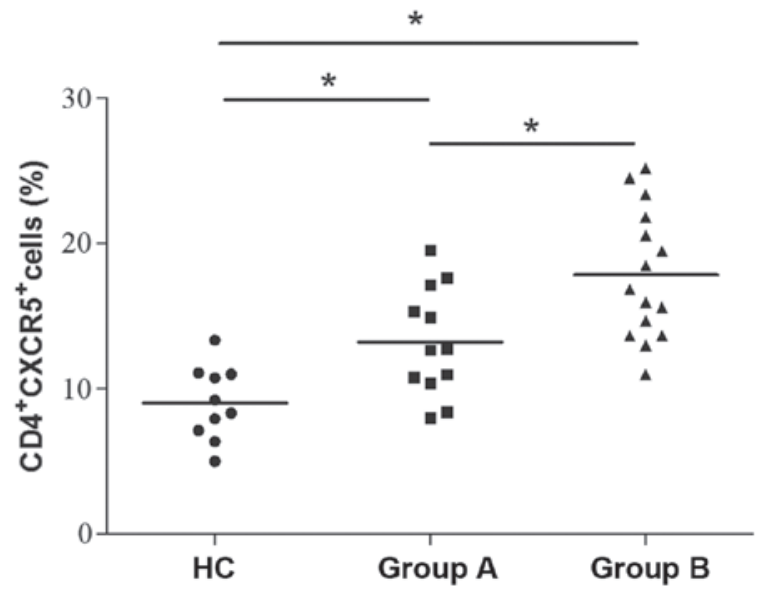

Figure 2. Fluorescence-activated cell sorting analysis of the frequency of Tfh cells. Peripheral blood mononuclear cells $\left(5 \times 10^{5}\right)$ were stained with anti-CXCR5 PerCP and anti-CD4 APC for detection of the Tfh cells. (A) Representative results for the frequency of each group of Tfh cells, measured using flow cytometry. (B) Percentage of Tfh cells in the immunoglobulin A nephropathy (group A and B) and HC groups ( ${ }^{*} \mathrm{P}<0.05$ ). Each data point represents an individual subject, and horizontal lines represent the median. Tfh, follicular helper T; HC, healthy control; SSC, side scatter; FSC, forward scatter; group A, 24-h proteinuria <4 g; group B, 24-h proteinuria $\geq 4 \mathrm{~g}$.

\section{Results and Discussion}

Increased frequencies of different B cell subsets in IgAN. IgAN is characterized by circulating immune complexes, composed of galactose-deficient IgA1 and a glycan-specific IgG antibody $(12,13)$, which is secreted by plasma cells. To determine the immune status of B cells in IgAN, 27 patients with IgAN were recruited in the present study and were divided into two groups: Group A, proteinuria/24 h $<4 \mathrm{~g}$ and group B, proteinuria/24 h $\geq 4$ g. No statistically significant differences were observed in the level of glomerular filtration rate or the distribution of age and gender between the IgAN groups and the HC group (Table I).

Marked increases in the percentages of CD19+CD138+ plasma cells, CD19+CD27+ memory B cells and CD19+CD86+ activated B cells (14-16) were observed in the IgAN groups, compared with the HC group. Although no significant difference in the percentage of plasma B cells was observed between the two IgAN groups, higher levels of memory and activated B cells were observed in the IgAN group B, compared with the group A (Fig. 1). These data indicated that the frequencies of memory and activated B cells were associated with the progression of IgAN.

Frequencies of circulating Tfh cells are higher in IgAN. Tfh cells are a subset of T cells that localize in the GC and specialize in assisting B cell growth, differentiation and class switching (17). Tfh cells are characterized by increased expression levels of molecules, including CXCR5, PD-1, ICOS, CD40L and IL-21, and reduced expression of CCR7. 
A

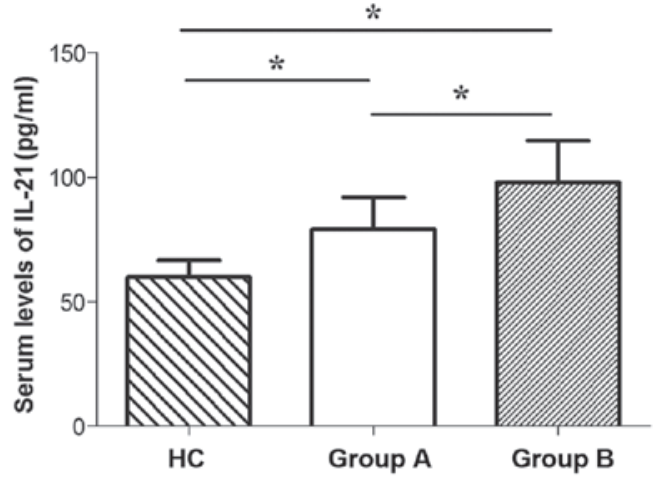

B

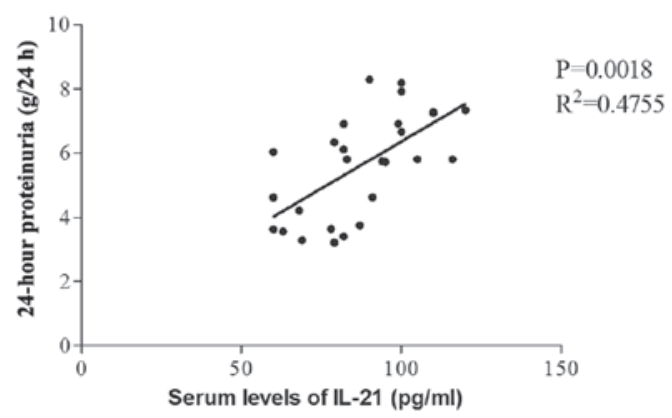

Figure 3. Concentration of serum IL-21, detected using ELISA. Positive correlation of increased serum IL-21 and circulating Tfh cells. (A) Increased serum levels of IL-21 were observed in the two IgAN groups (group A and B; $\mathrm{P}<0.05$ ). (B) Serum IL-21 was positively correlated with the extent of 24-h proteinuria in the IgAN patients. Data are expressed as the mean \pm standard deviation of individual participants from two separate experiments. The horizontal lines indicate the median values of different groups. IL-21, interleukin-21; IgAN, immunoglobulin A nephropathy; HC, healthy contol.

The CD4+CXCR5+ T cells have been previously identified as Tfh cells (18-20), and the present study demonstrated that the frequency of CD4+CXCR5+ Tfh cells was significantly higher in the two IgAN groups, compared with that in the $\mathrm{HC}$ group. In addition, the percentage of Tfh cells was higher in the IgAN group B than group A (Fig. 2). These data indicated that high levels of Tfh cells may accelerate IgAN exacerbation by promoting the proliferation and function of $\mathrm{B}$ cells.

Serum IL-21 levels are increased in patients with IgAN. As a key effector of Tfh cells, IL-21 is involved in the process of promoting the growth, differentiation and class switching of B cells $(21,22)$. Due to the high frequency of Tfh cells observed in the patients with IgAN, the concentration of IL-21 in the serum was also determined in the in above-mentioned groups. The results of the ELISA indicated that the concentration of serum IL-21 in group B was significantly higher than that in either group A or the HC group (Fig. 3A). Furthermore, the serum levels of IL-21 were positively correlated with the extent of 24-h proteinuria (Fig. 3B), which indicated serum IL-21 may act as a biomarker for IgAN.

Effect of IL-21 on AID in IgAN. AID belongs to the APOBEC family of cytidine deaminases and is capable of deaminating $\mathrm{dCs}$ into dUs in vitro on ssDNA substrates and ssDNA generated by the formation of RNA-DNA hybrids $(10,23)$. The key function of AID is to induce somatic hypermutation (SHM),
A

IL-21

AID

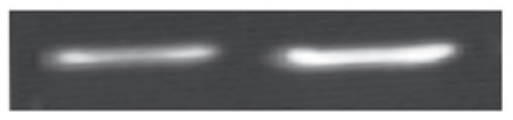

GAPDH

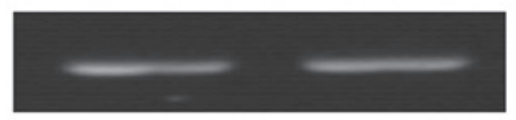

$\mathbf{B}$

IL-21

AID

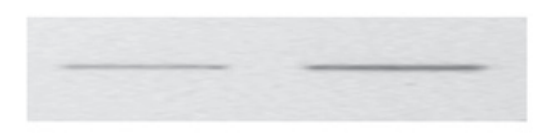

GAPDH

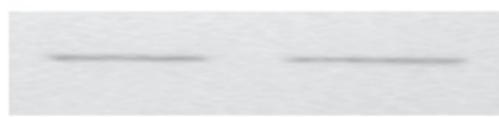

Figure 4. Effect of IL-21 on the expression of AID. Recombinant human IL-21 was added into B cells from healthy volunteers to verify the transcriptional and translational levels of intracellular AID in the B cells. (A) mRNA level of AID in sorted B cells. (B) Translational expression of AID in sorted B cells. A significant increase in AID in was observed in the IL-21-treated group, compared with the group without IL-21. The experiment was repeated a minimum of three times. IL-21, interleukin-21; AID, activation-induced cytidine deaminase.

Ig class-switch recombination (CSR) and gene conversion $(11,24,25)$. IgA class switching occurs in $\operatorname{IgAN}(26,27)$, therefore, the present study investigated whether the high levels of IL-21 were associated with the expression of AID. Following culture of the B cells in vitro, a significantly increasing level of AID was observed in the IL-21-treated group (Fig. 4). This suggested that the excessive production of $\operatorname{IgA}$ may be mediated by the high levels of IL-21 secreted by Tfh cells.

IgAN is characterized by circulating immune complexes, which are composed of galactose-deficient $\operatorname{IgA} 1$ and a glycan-specific IgG antibody. In addition, antigen-antibody immune complexes against hepatitis B (HB) surface, HB core or HB e antigens, together with complement components, have been demonstrated to be deposited in renal tissue $(28,29)$. $\mathrm{B}$ cells are considered to be the key regulators of IgA production in mucosal tissues, and CD138, CD86 and CD27 are reliable markers, which are expressed by different subsets of B cells $(30,31)$. In the present study, CD19+CD138+ cells were defined as plasma cells, CD19+CD27+ cells as memory $\mathrm{B}$ cells and CD19+CD86+ cells as activated B cells, and the frequencies of these subsets of B cells were analyzed in patients with IgAN. Significant increases in the percentage of these three subsets of B lymphocytes were observed in the two IgAN groups, compared with the HC group. Furthermore, the frequencies of memory and activated $\mathrm{B}$ cells in the advanced IgAN group (group B) were markedly higher than that of the less advanced IgAN group (group A). Notably, although the IgA produced by plasma cells mediated immune complex deposition in the glomerular mesangial area, resulting in IgAN, the numbers of plasma cells were not significantly different between the IgAN groups. These data indicated that high levels of memory and activated $\mathrm{B}$ cells resulted in the progression of $\operatorname{IgAN}$, however, but that the $\operatorname{IgA}$ immune complex deposition was not solely associated with excessive IgA secretion by the plasma cells. Hernández et al (32), demon- 
strated that levels of plasma von Willebrand Factor, a specific marker for endothelial cell injury, are abnormal in patients with IgAN, who exhibit elevated levels or defective molecules. Elevated levels of sFlt-1, a receptor for vascular endothelial growth factor, may lead to widespread endothelial dysfunction and also contributes to the progression of $\operatorname{IgAN}(33)$. Thus, the IgA immune complex deposition is associated with immune cells and abnormal endothelial function.

Regarding the effect of Tfh cells on B cell differentiation and activation, the frequency of Tfh cells was analyzed in PBMCs in the present study. CD4+CXCR5+ T cells were identified as Tfh cells, and the frequency of circulating Tfh cells was higher in the advanced $\operatorname{IgAN}$ group than in the less advanced IgAN group, which was similar to the results observed in the memory and activated B cells. Although Tfh cells activate the proliferation and differentiation of B cells, the selective stimulation targeting different subsets of $\mathrm{B}$ cells requires further investigation. Tfh cells are classified into three subsets: Tfh1, Tfh2 and Tfh17, (CXCR3+CCR6CXCR3-CCR6- and CXCR3-CCR6+ cells, respectively) (20). In addition, Tfh 2 and Tfh17 cells have been reported to assist in the activation of B cells via the production of IL-21, resulting in the secretion of various isotypes, including $\operatorname{IgM}$, $\operatorname{IgA}$ and $\operatorname{IgG}$, and IgE for Tfh2 cells (20). Thus, the present study hypothesized that different B cell subsets are stimulated by different Tfh cell subsets, warranting investigation of the mechanism underlying the regulation of Tfh cells.

As a key effector of activated Tfh cells, IL-21 induces $B$ cell proliferation, mediates the differentiation of activated B cells into plasma and promotes IgM, IgG and IgA production $(34,35)$. Thus, the concentration of serum IL-21 was investigated, which revealed that increased levels of IL-21 were positively correlated with the extent of $24 \mathrm{~h}$ proteinuria. Thus, the activation of B cells was suggested to be predominantly mediated by high levels of IL-21 secreted by Tfh cells, and IL-21 may act as a biomarker of IgAN progression.

The association between high levels of IL-21 and the expression of AID was subsequently investigated to clarify the function of IL-21. By stimulating B cells using recombinant human IL-21, a significant upregulation of AID was observed. This indicated that IL-21 was positively associated with the expression of AID expression in B cells. As a cytidine deaminase, the predominant function of AID is inducing SHM and Ig CSR $(11,24,25)$ in GC or GC-like states at extrafollicular locations (36). In the GC, B cells differentiate into either plasma cells, which secrete antibodies, or memory cells, enabling long-term memory of antigens (37). IgA CSR is important during the process of IgA production. B cell activation factor has been reported to induce the expression of germline AID and $\operatorname{Ig}$ A class switching in a CD40-independent manner (38). Therefore, a high level of AID is a key mediator for excessive IgA production, resulting in the development of $\operatorname{IgAN}$. The activity of AID is regulated at the transcriptional level by HoxC4 and nuclear factor- $\kappa \mathrm{B}$, and at the translational level by AID phosphorylation and ubiquitination (39-42). The results of the present study confirmed that IL-21 enhanced the expression of AID. Therefore, it was hypothesized that high levels of IL-21 secreted by Tfh cells may promote the differentiation of B cells and induce IgA CSR in patients with $\operatorname{IgAN}$.
The data of the present study demonstrated that the progression of $\operatorname{IgAN}$ was closely associated with high levels of memory B cells, activated B cells and Tfh cells, and that the potential mechanism was predominantly associated with the selective effect of Tfh cells on different B cell subsets. The significantly increased levels of IL-21 upregulated the expression of AID in the B cells, which mediated IgA class switching during the differentiation of activated $\mathrm{B}$ cells into plasma B cells. However, further investigation is required to fully elucidate the selective mechanism underlying the stimulation of different types of Ig.

\section{Acknowledgements}

The authors would like to thank Dr Munan Sun (Jilin Province People's Hospital) for the collection of clinical samples and supporting information.

\section{References}

1. D'Amico G: The commonest glomerulonephritis in the world: IgA nephropathy. Q J Med 64: 709-727, 1987.

2. Endo $\mathrm{Y}$ and Kanbayashi H: Etiology of $\operatorname{IgA}$ nephropathy syndrome. Pathol Int 44: 1-13, 1994.

3. Galla JH: IgA nephropathy. Kidney Int 47: 377-387, 1995.

4. Das A, Ellis G, Pallant C, Lopes AR, Khanna P, Peppa D, Chen A, Blair P, Dusheiko G, Gill U, et al: IL-10 producing regulatory $\mathrm{B}$ cells in the pathogenesis of chronic hepatitis B virus infection. J Immunol 189: 3925-3935, 2012.

5. Suzuki Y, Suzuki H, Nakata J, Sato D, Kajiyama T, Watanabe T and Tomino Y: Pathological role of tonsillar B cells in IgA Nephropathy. Clin Dev Immunol 2011: 639074, 2011.

6. Suzuki H, Suzuki Y, Narita I, Aizawa M, Kihara M, Yamanaka T, Kanou T, Tsukaguchi H, Novak J, Horikoshi S, et al: Toll-like receptor 9 affects severity of IgA nephropathy. J Am Soc Nephrol 19: 2384-2395, 2008.

7. Iwata Y, Wada T, Uchiyama A, Miwa A, Nakaya I, Tohyama T, Yamada Y, Kurokawa T, Yoshida T, Ohta S, et al: Remission of IgA nephropathy after allogeneic peripheral blood stem cell transplantation followed by immunosuppression for acute lymphocytic leukemia. Intern Med 45: 1291-1295, 2006.

8. Ozaki K, Kikly K, Michalovich D, Young PR and Leonard WJ: Cloning of a type I cytokine receptor most related to the IL-2 receptor beta chain. Proc Natl Acad Sci USA 97: 11439-11444, 2000 .

9. Leonard WJ: Cytokines and immunodeficiency diseases. Nat Rev Immunol 1: 200-208, 2001.

10. Chaudhuri J, Tian M, Khuong C, Chua K, Pinaud E and Alt FW: Transcription-targeted DNA deamination by the AID antibody diversification enzyme. Nature 422: 726-730, 2003.

11. Muramatsu M, Kinoshita K, Fagarasan S, Yamada S, Shinkai Y and Honjo T: Class switch recombination and hypermutation require activation-induced cytidine deaminase (AID), a potential RNA editing enzyme. Cell 102: 553-563, 2000.

12. Barratt J, Feehally J and Smith AC: Pathogenesis of $\operatorname{Ig} A$ nephropathy. Semin Nephrol 24: 197-217, 2004.

13. Wang NS, Wu ZL, Zhang YE, Guo MY and Liao LT: Role of hepatitis B virus infection in pathogenesis of $\operatorname{IgA}$ nephropathy. World J Gastroenterol 9: 2004-2008, 2003.

14. Arpin C, Déchanet J, Van Kooten C, Merville P, Grouard G, Brière $F$, Banchereau $J$ and Liu YJ: Generation of memory B cells and plasma cells in vitro. Science 268: 720-722, 1995.

15. aan de Kerk DJ, Jansen MH, ten Berge IJ, van Leeuwen EM and Kuijpers TW: Identification of B cell defects using age-defined reference ranges for in vivo and in vitro B cell differentiation. J Immunol 190: 5012-5019, 2013.

16. Klein U, Rajewsky K and Küppers R: Human immunoglobulin (Ig)M+IgD+ peripheral blood B-cells expressing the CD27 cell surface antigen carry somatically mutated variable region genes: CD27 as a general marker for somatically mutated (memory) B-cells. J Exp Med 188: 1679-1689, 1998. 
17. Fazilleau N, Mark L, McHeyzer-Williams LJ and McHeyzer-Williams MG: Follicular helper T cells: Iineage and location. Immunity 30: 324-335, 2009.

18. Linterman MA, Liston A and Vinuesa CG: T-follicular helper cell differentiation and the co-option of this pathway by non-helper cells. Immunol Rev 247: 143-159, 2012.

19. Linterman MA and Vinuesa CG: T follicular helper cells during immunity and tolerance. Prog Mol Biol Transl Sci 92: 207-248, 2010.

20. Morita R, Schmitt N, Bentebibel SE, Ranganathan R, Bourdery L, Zurawski G, Foucat E, Dullaers M, Oh S, Sabzghabaei N, et al: Human blood CXCR5 (+) CD4 (+) T cells are counterparts of $\mathrm{T}$ follicular cells and contain specific subsets that differentially support antibody secretion. Immunity 34: 108-121, 2011.

21. Ettinger R, Kuchen S and Lipsky PE: The role of IL-21 in regulating B-cell function in health and disease. Immunol Rev 223 60-86, 2008

22. Spolski R and Leonard WJ: Interleukin-21: Basic biology and implications for cancer and autoimmunity. Annu Rev Immunol 26: 57-79, 2008

23. Ramiro AR, Stavropoulos P, Jankovic M and Nussenzweig MC: Transcription enhances AID-mediated cytidine deamination by exposing single-stranded DNA on the nontemplate strand. Nat Immunol 4: 452-456, 2003

24. Jacob J, Kelsoe G, Rajewsky K and Weiss U: Intraclonal generation of antibody mutants in germinal centres. Nature 354: 389-392, 1991

25. Muramatsu M, Sankaranand VS, Anant S, Sugai M, Kinoshita K, Davidson NO and Honjo T: Specific expression of activation-induced cytidine deaminase (AID), a novel member of the RNA-editing deaminase family in germinal center B cells. J Biol Chem 274: 18470-18476, 1999.

26. van Vlassaelaer P, Punnonen J and de Vries JE: Transforming growth factor-beta directs IgA switching in human B cells. J Immnol 148: 2062-2067, 1992.

27. Baskin B, Pettersson E, Rekola S, Smith CI and Islam KB: Studies of the molecular basis of IgA production, subclass regulation and class-switch recombination in IgA nephropathy patients. Clin Exp Immunol 106: 509-517, 1996.

28. He XY, Fang LJ, Zhang YE, Sheng FY, Zhang XR and Guo MY: In situ hybridization of hepatitis B DNA in hepatitis B-associated glomerulonephritis. Pediatr Nephrol 12: 117-120, 1998.

29. Wu ZL, Wang NS, Xu XH, Qiu LQ, Zhou Q, Zhang YE: Positive and negative hepatitis $\mathrm{B}$ virus in renal biopsies of IgA nephropathy: An 85-case clinicopathological analysis. Nephrology 6: 185-189, 2001
30. LeBien TW and Tedder TF: B lymphocytes: how they develop and function. Blood 112: 1570-1580, 2008.doi: 10.1182/blood-2008-02-078071.

31. Odendahl M, Jacobi A, Hansen A, Feist E, Hiepe F, Burmester GR, Lipsky PE, Radbruch A and Dörner T: Disturbed peripheral B lymphocyte homeostasis in systemic lupus erythematosus. J Immunol 165: 5970-5979, 2000.

32. Hernández E, Toledo T, Alamo C, Mon C, Rodicio JL and Praga M: Elevation of von Willebrand factor levels in patients with IgA nephropathy: Effect of ACE inhibition. Am J Kidney Dis 30: 397-403, 1997.

33. Zhai YL, Zhu L, Shi SF, Liu LJ, Lv JC and Zhang H: Elevated soluble VEGF receptor sFlt-1 correlates with endothelial injury in IgA nephropathy. PLoS One 9: e101779, 2014.

34. Konforte D, Simard N and Paige CJ: IL-21: An executor of B cell fate. J Immunol 182: 1781-1787, 2009.

35. Bryant VL, Ma CS, Avery DT, Li Y, Good KL, Corcoran LM, de Waal Malefyt R and Tangye SG: Cytokine-mediated regulation of human $\mathrm{B}$ cell differentiation into Ig-secreting cells: Predominant role of IL-21 produced by CXCR 5+ T follicular helper cells. J Immunol 179: 8180-8190, 2007.

36. Cattoretti G, Büttner M, Shaknovich R, Kremmer E, Alobeid B and Niedobitek G: Nuclear and cytoplasmic AID in extrafollicular and germinal center B cells. Blood 107: 3967-3975, 2006

37. Good-Jacobson KL, Szumilas CG, Chen L, Sharpe AH, Tomayko MM and Shlomchik MJ: PD-1 regulates germinal center B cell survival and the formation and affinity of long-lived plasma cells. Nat Immunol 11: 535-542, 2010.

38. Liu H, Peng Y, Liu F, Xiao W, Zhang Y and Li W: Expression of $\operatorname{IgA}$ class switching gene in tonsillar mononuclear cells in patients with IgA nephropathy. Inflamm Res 60: 869-878, 2011.

39. Xu Z, Zan H, Pone EJ, Mai T and Casali P: Immunoglobulin class-switch DNA recombination: Induction, targeting and beyond. Nat Rev Immunol 12: 517-531, 2012

40. McBride KM, Gazumyan A, Woo EM, Schwickert TA, Chait BT and Nussenzweig MC: Regulation of class switch recombination and somatic mutation by AID phosphorylation. J Exp Med 205: 2585-2594, 2008

41. Basu U, Wang Y and Alt FW: Evolution of phosphorylation-dependent regulation of activation-induced cytidine deaminase. Mol Cell 32: 285-291, 2008.

42. Aoufouchi S, Faili A, Zober C, D'Orlando O, Weller S, Weill JC and Reynaud CA: Proteasomal degradation restricts the nuclear lifespan of AID. J Exp Med 205: 1357-1368, 2008. 